Thorax, 1981, 36, 149-150

\title{
Chronic pericardial effusion after mediastinal radiotherapy
}

\author{
STEPHANIE A GOMM AND T B STRETTON
}

From the Department of Respiratory Medicine, Manchester Royal Infirmary, Manchester

The pericardial complications which may follow mediastinal radiotherapy usually occur within five years of treatment. ${ }^{2}$ Acute pericarditis may occur early during treatment and chronic pericardial effusion or constrictive pericarditis may develop months or years later. A patient is reported who presented with a chronic pericardial effusion 12 years after radiotherapy for stage IIA Hodgkin's disease.

\section{Case report}

In 1966, a 39-year old man, while working in the United States, received radiotherapy for Hodgkin's disease involving bilateral cervical and mediastinal lymph nodes. The mediastinal lymph nodes were treated by an anterior field, receiving a mid-plane dose of 4100 rads given over 29 days. There was no subsequent recurrence. In June 1978 he presented with a six-month history of dyspnoea on exertion but no symptoms of orthopnoea or ankle oedema.

On examination he had marked radiation-induced skin fibrosis over the sternum. He was afebrile. His pulse was $96 / \mathrm{min}$ with a small volume and his blood pressure $100 / 80 \mathrm{~mm} / \mathrm{Hg}$. The jugular venous pressure was not elevated. The heart sounds were normal. The percussion note was dull and the breath sounds decreased at the right lung base. There was no evidence of ankle oedema, hepatomegaly, or ascites. A chest radiograph (fig 1) showed an apparently elevated right hemidiaphragm with clear lung fields and no mediastinal gland involvement. The cardiothoracic diameter ratio (CTR) was $20 / 34 \mathrm{~cm}$. A decubitus film revealed a right sub-pulmonary effusion. An electrocardiogram showed low voltage complexes and right bundle branch block.

Aspirated pleural fluid was straw coloured with a protein content of $54 \mathrm{~g} / 1$ and glucose $6.4 \mathrm{mmol} / 1$. The predominant cell type was lymphocytic with no evidence of Reed-Sternberg or other malignant cells. Cultures for acid-fast bacilli were negative. Echocardiography confirmed the presence of a pericardial effusion and $600 \mathrm{ml}$ of clear straw-coloured fluid were aspirated. As with the pleural fluid, there was no evidence of Hodgkin's disease or tuberculosis. The CTR after pericardiocentesis was $14 / 34 \mathrm{~cm}$ (fig 1). Results of other investigations were: haemoglobin $14.8 \mathrm{~g} / \mathrm{dl}$; white cell count $6.9 \times 10^{9} / 1$; erythrocyte sedimentation rate $7 \mathrm{~mm} / \mathrm{hr}$; total serum proteins, $75 \mathrm{~g} / \mathrm{l}$; albumin $40 \mathrm{~g} / 1$. Serum thyroxine was normal

Address for reprint requests: Dr TB Stretton, Department of Respiratory Medicine, Manchester Royal Infirmary, Oxford Road, Manchester M13 9WL. at $85 \mathrm{nmol} / \mathrm{l}$. Anti-nuclear factor and LE cells were not present and viral studies were all normal.

In spite of initial improvement after the aspirations, two months later he was breathless on minimal exertion; the pericardial fluid had reaccumulated as judged by echocardiography and an increase in the cardiac size radiologically. On clinical examination he did not have pulsus paradoxus, elevation of jugular venous pressure, ascites, or peripheral oedema. Pericardectomy was advised for diagnostic and therapeutic reasons, particularly in view of the possibility of cardiac tamponade.

A $9.0 \times 5.0 \mathrm{~cm}$ pericardial window over the left side of the heart was made as far laterally as the phrenic

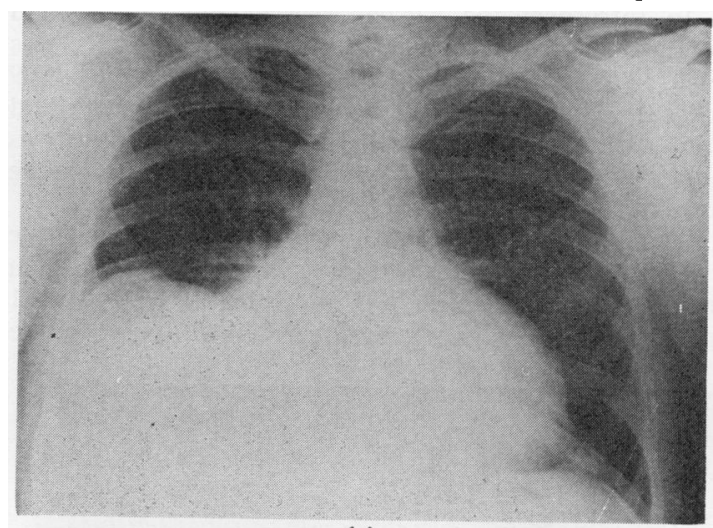

(a)

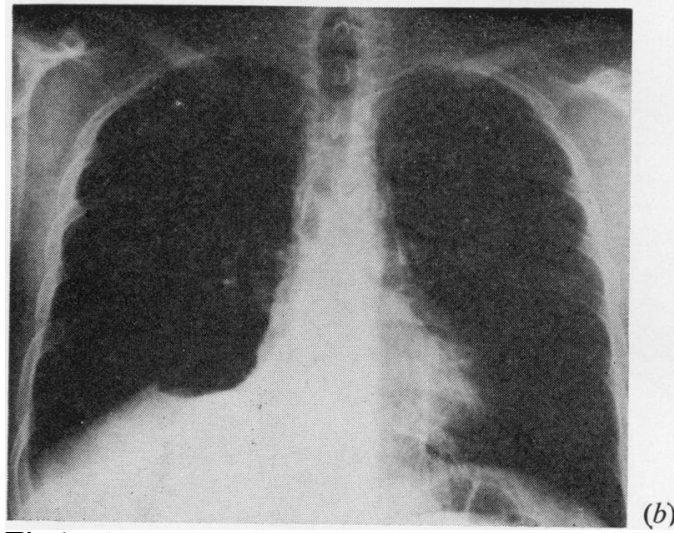

Fig 1 (a) Posteroanterior chest radiograph showing a pericardial and right pleural effusion simulating an elevated diaphragm. (b) After pleural and pericardial aspiration. 
nerve, upwards over the left atrium and medially almost to the mid-line. Macroscopically the pericardium was described as only slightly thickened. Histology showed fibrous thickening with patchy, focal non-specific cell infiltrate of mature lymphocytes and plasma cells. There was no evidence of recurrence of Hodgkin's disease.

Since the operation his effort tolerance has improved but he fatigues easily and requires regular treatment with digoxin and diuretics. There has been no reaccumulation of pericardial or pleural fluid. Right bundle branch block persists.

\section{Discussion}

The development of radiation-induced pericarditis is related to the radiation dose given to the heart, usually over 4000 rads. $^{3}$ In 1966 , the treatment regimen used for this patient was based on the upper mantle technique using Cobalt 60,4 the total dose to the heart exceeding 4100 rads. Smithers ${ }^{5}$ using a similar technique recorded no significant heart damage between 1963 and 1970 with doses of 3500 rads to the heart.

In retrospect the cardiac size of our patient had already increased in 1974, when the CTR was $17 \cdot 0 / 34.0 \mathrm{~cm}$ compared to $14.5 / 34.0 \mathrm{~cm}$ in 1969 (fig 2). This indicates a slow accumulation of fluid into a distensible pericardial cavity. At no time was there evidence of constrictive pericarditis or acute cardiac tamponade.

The description of the pericardial fluid and the histology of the pericardium is very similar to that reported by Martin et al,1 in which a series of 81 patients with Hodgkin's disease received upper mantle

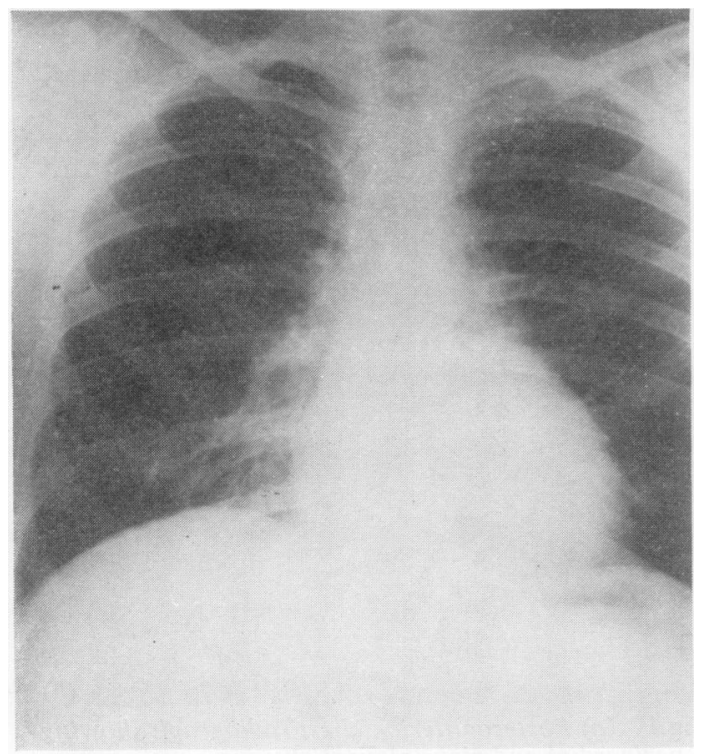

(a) radiotherapy (4600 rads to the heart). Ten of these patients developed chronic pericardial effusion.

The mechanism for the development of a peri cardial effusion 12 years after radiotherapy in ou patient is uncertain but it may be the result of fibrosis of the pericardium and its lymphatics. In thise and other cases of large persistent pericardial effusions the prognosis is uncertain. Morton et $a l^{2}$ recom:mended surgery in all symptomatic patients. Close follow-up of asymptomatic patients is recommended in view of the danger of tamponade. This patient and others treated with high dose mediastinal irradiation illustrate that long-term surveillance may be neede $\$$ in view of the possible development of cardiaes abnormalities and in particular late pericardia $\vec{P}$ complications.

We wish to thank Dr Ian Todd and Mr Harold Basset for their help with this patient.

\section{References}

1 Martin RG, Ruikdeschel JC, Chang $\mathbf{P}$ et alg Radiation related pericarditis. Am J Cardiol 1975, 2:216-20.

2 Morton DL, Glancy DL, Joseph WL et a Management of patients with radiation induced pericarditis with effusion. Chest 1973; 64:291-7.

3 Cohn KE, Stewart JR, Fayardo LF et al. Hearf disease following radiation. Medicine 1967; 46క 281-9.

4 Kaplan HS. Clinical evaluation and radio therapeutic management of Hodgkin's diseas and the malignant lymphomas. N Engl J Med 1968; 278:892-9.

5 Smithers D. Hodgkin's disease. Edinburgh an London: Churchill Livingstone, 1973; 204-8.

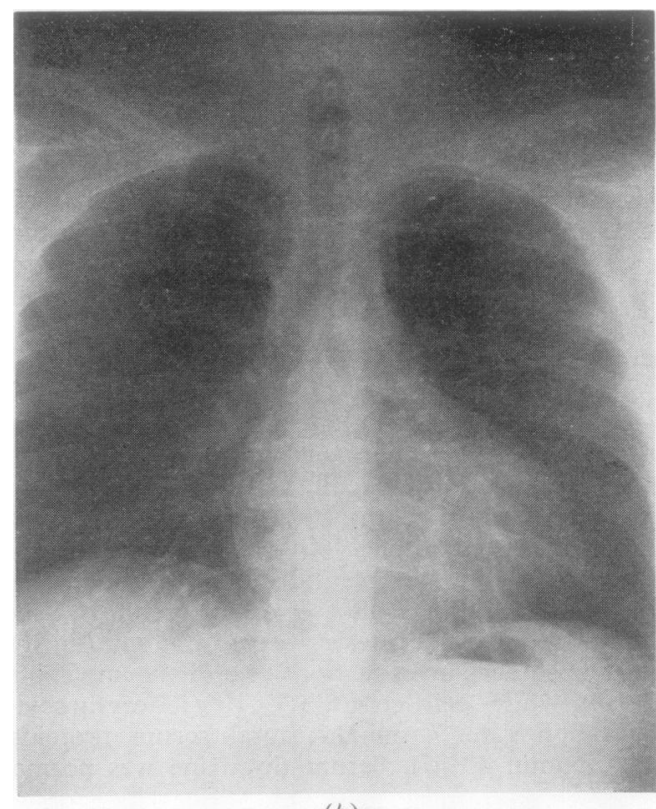

(b)

Fig 2 (a) Chest radiograph 1969, CTR was 14.5/34 cm. (b) Chest radiograph 1974, CTR was $17 / 34 \mathrm{~cm}$. 